\title{
Long-term insulin glargine therapy in type 2 diabetes mellitus: a focus on cardiovascular outcomes
}

This article was published in the following Dove Press journal:

Vascular Health and Risk Management

28 January 2015

Number of times this article has been viewed

\author{
Joshua J Joseph \\ Thomas W Donner \\ Division of Endocrinology, Diabetes \\ and Metabolism, Department of \\ Medicine, Johns Hopkins University \\ School of Medicine, Baltimore, \\ MD, USA
}

\begin{abstract}
Cardiovascular disease is the leading cause of mortality in type 2 diabetes mellitus. Hyperinsulinemia is associated with increased cardiovascular risk, but the effects of exogenous insulin on cardiovascular disease progression have been less well studied. Insulin has been shown to have both cardioprotective and atherosclerosis-promoting effects in laboratory animal studies. Long-term clinical trials using insulin to attain improved diabetes control in younger type 1 and type 2 diabetes patients have shown improved cardiovascular outcomes. Shorter trials of intensive diabetes control with high insulin use in higher risk patients with type 2 diabetes have shown either no cardiovascular benefit or increased all cause and cardiovascular mortality. Glargine insulin is a basal insulin analog widely used to treat patients with type 1 and type 2 diabetes. This review focuses on the effects of glargine on cardiovascular outcomes. Glargine lowers triglycerides, leads to a modest weight gain, causes less hypoglycemia when compared with intermediate-acting insulin, and has a neutral effect on blood pressure. The Outcome Reduction With Initial Glargine Intervention (ORIGIN trial), a 6.2 year dedicated cardiovascular outcomes trial of glargine demonstrated no increased cardiovascular risk.
\end{abstract}

Keywords: glargine, insulin, type 2 diabetes, cardiovascular disease, cardiovascular outcomes

\section{Background}

Cardiovascular disease is the leading cause of death among patients with diabetes mellitus. A role of insulin therapy in the development or progression of atherosclerosis has been proposed due to associations of hyperinsulinemia with atherosclerosis. ${ }^{1}$ Hyperinsulinemia is found in nondiabetic patients with coronary artery disease ${ }^{2}$ and is closely associated with other cardiovascular risk factors including hypertension and dyslipidemia. Atherosclerotic changes have been seen in animal studies following long-term treatment with insulin, including the development of lipid-containing arterial lesions and arterial wall thickening. ${ }^{3}$

Cardiovascular disease in type 2 diabetes mellitus involves complex pathophysiology that is promoted by traditional risk factors such as hypertension, dyslipidemia, hyperglycemia, tobacco smoking, physical inactivity, obesity, and novel risk factors including pro-inflammatory cytokines, clotting factors, sleep insufficiency, stress, and socioeconomic status. ${ }^{4}$ Treatment of cardiovascular disease risk factors is known to reduce cardiovascular events. Unfortunately, treatment targets are often unmet. In a cross sectional analysis from 2010 , only $18.8 \%$ of persons with type 2 diabetes in the United States met goals for blood pressure, lipids and glycemic control. ${ }^{5}$
Correspondence: Thomas W Donne

Division of Endocrinology,

Diabetes and Metabolism,

Department of Medicine

Johns Hopkins University School

of Medicine, 60I North Caroline Street,

Suite 2008, Baltimore, MD 21287, USA

$\mathrm{Tel}+\mathrm{I} 4109552908$

Fax + I 4106149586

Email tdonnerI@jhmi.edu 
Type 2 diabetes is a disorder characterized by progressive insulin deficiency, leading to a greater need for insulin to control hyperglycemia with increasing duration of disease. Glargine insulin, a basal insulin analog having a duration of action of about 24 hours, is the most commonly initiated insulin among patients with uncontrolled diabetes in the United States and among the best-studied. This review will discuss cardiovascular disease in type 2 diabetes, the effects of glycemic control and insulin therapy on cardiovascular disease, and focus specifically on the cardiovascular effects of glargine insulin.

\section{Type 2 diabetes mellitus and cardiovascular disease}

Cardiovascular disease is a major cause of morbidity and mortality in type 2 diabetes, leading to a two to four-fold increased risk of cardiovascular events and a three-fold increase in cardiovascular mortality. ${ }^{6}$ In a 1998 study of 2,432 patients, the 7 year incidence of fatal and nonfatal myocardial infarction (MI) was found to be similar (about 20\%) in persons with diabetes and no prior MI when compared with persons with a previous MI but no diabetes. ${ }^{7}$ The presence of type 2 diabetes is now widely considered a cardiovascular risk equivalent.

\section{Glycemic control and cardiovascular disease reduction}

There remains controversy surrounding the effects of glycemic control on cardiovascular risk. Large studies in type 1 and type 2 diabetes have demonstrated reduced cardiovascular events after improved glycemic control with longterm follow-up. The first trial to identify a role of glycemic control in cardiovascular endpoints was the Epidemiology of Diabetes Interventions and Complications (EDIC) study, ${ }^{8}$ the long-term follow-up study of the Diabetes Control and Complications Trial (DCCT). ${ }^{9}$ The DCCT enrolled 1,441 type 1 diabetes subjects ages $13-39$ years without a history of cardiovascular disease into a control conventional therapy group consisting of 1-2 injections of insulin, self-monitored blood glucose or urine testing and diabetes education with no change in therapy unless the glycated hemoglobin $\left(\mathrm{HbA}_{1 \mathrm{c}}\right.$ ) rose to $>13.1 \%$, and compared it to an intensive intervention group with multiple daily injections or insulin pump therapy and a goal $\mathrm{HbA}_{1 \mathrm{c}}$ of $<6.05 \%$. The initial DCCT was not powered to study cardiovascular disease due to low cardiovascular events rates in this young patient population with a short duration of diabetes, which excluded patients with hypertension or hyperlipidemia. The intensive intervention group attained an $\mathrm{HbA}_{1 \mathrm{c}}$ of $7.2 \%$ compared to
$9.1 \%$ in the control group. After a mean 6.5 years of patient follow-up, marked reductions in microvascular complications were observed among those intensively controlled. All study patients were thereafter offered intensive insulin therapy, and followed annually in the EDIC trial. After a mean 18 years of follow-up from the start of the DCCT, previously intensively controlled patients had a $42 \%$ reduction in the primary cardiovascular disease outcome (major nonfatal and fatal cardiovascular disease events, angina, or revascularization) and a 57\% reduction in fatal and nonfatal MI, and stroke. ${ }^{8}$ This cardiovascular event reduction was supported by surrogate endpoints including reduced coronary artery calcification ${ }^{10}$ and reduced carotid intima media thickness (CIMT) among those who received intensive insulin therapy. ${ }^{11-13}$

The United Kingdom Prospective Diabetes Study (UKPDS) was the first study to investigate the effects of intensive diabetes management on complications in patients with type 2 diabetes. Over 3,800 subjects with newly diagnosed type 2 diabetes were randomized to intensive control with a sulfonylurea or insulin, or to conventional care with diet alone and followed for 10 years..$^{14}$ Mean $\mathrm{HbA}_{1 \mathrm{c}}$ attained was $7.0 \%$ in the intensive therapy group and $7.9 \%$ in the conventional therapy group. Results showed a $21 \%$ risk reduction in microvascular endpoints with intensive therapy, a non-significant $16 \%(P=0.052)$ decrease in fatal and nonfatal MI, and a non-significant $6 \%(P=0.44)$ decrease in all cause mortality. A follow-up epidemiological assessment 10 years post-trial conclusion revealed significant cardiovascular disease reduction. Intensive therapy led to $15 \%$ reduction in MI, and all cause mortality was reduced by $13 \% .{ }^{15}$ UKPDS $34^{16}$ assessed cardiovascular disease reduction in over 1,700 overweight patients with type 2 diabetes randomized to metformin, intensive therapy with insulin/sulfonylurea or conventional treatment with diet alone. The mean $\mathrm{HbA}_{1 \mathrm{c}}$ was $7.4 \%$ in the metformin and insulin/sulfonylurea groups versus (vs) $8.0 \%$ in the conventional treatment group after 10 years. Only the metformin group had significant reductions in MI (39\%) and all cause mortality (36\%). The UKPDS results form the basis of our current practice to use metformin as first line therapy in type 2 diabetes and to target improved glycemic control. Among patients treated primarily with diet, insulin or a sulfonylurea, each $1 \%$ reduction in mean $\mathrm{HbA}_{1 \mathrm{c}}$ was associated with significant reductions in risk of $21 \%$ for any microvascular or macrovascular end point related to diabetes, $21 \%$ for deaths related to diabetes, and $14 \%$ for MI regardless of treatment group. ${ }^{17}$

The reduction in cardiovascular disease seen in UKPDS led to the design of intensive diabetes control studies in 
type 2 diabetes subjects at increased risk for cardiovascular disease: Action to Control Cardiovascular Risk in Diabetes (ACCORD),${ }^{18}$ Action in Diabetes and Vascular Disease: Preterax and Diamicron Modified-Release Controlled Evaluation (ADVANCE), ${ }^{19}$ and Veterans Affairs Diabetes Trial (VADT). ${ }^{20}$ The target $\mathrm{HbA}_{1 \mathrm{c}}$ among intensively controlled subjects was $<6 \%$ in ACCORD, $<6.5 \%$ in ADVANCE, and a $1.5 \%$ reduction in $\mathrm{HbA}_{1 \mathrm{c}}$ compared to controls in VADT. After 3.5 to 5.6 years of follow-up, none of the studies showed significant reductions in cardiovascular disease. The ACCORD trial was stopped early due to a significant $22 \%$ increase in all cause and cardiovascular mortality with intensive glucose control. Insulin use in these three trials ranged from $24 \%-74 \%$ of subjects in the standard control groups and $41 \%-90 \%$ among intensively controlled subjects. Significant weight gain and increased rates of severe hypoglycemia were seen among intensively controlled subjects in all three trials.

Much debate remains as to the neutral or adverse cardiovascular outcomes seen in these three trials, and the beneficial effects seen in UKPDS. Significant differences in study populations and design likely play a role. Study subjects in ACCORD, ADVANCE, and VADT were older with a longer duration of diabetes at randomization, were targeted to a lower $\mathrm{HbA}_{1 \mathrm{c}}$, and had high rates of cardiovascular disease, $30 \%-40 \%$ at baseline. This suggests that patients with new onset type 2 diabetes without significant cardiovascular disease have better cardiovascular outcomes with intensive glycemic control and that there may be a "point of no return" after atherosclerosis is established beyond which there may be no added benefit, with a potential increased risk in older patients with a longer duration of disease or in those with known cardiovascular disease. This has led to the American Diabetes Association to advocate less stringent "individualized" $\mathrm{HbA}_{1 \mathrm{c}}$ targets for higher risk patients with known macrovascular disease..$^{21,22}$

\section{Insulin glargine}

Insulin glargine is a synthetic basal insulin analog with an 18-26 hour duration of action. Its prolonged duration of action results from the substitution of glycine for asparagine at position 21 of the A-chain of human insulin and the addition of two arginine residues to position 30 of the B-chain. The structural changes render glargine soluble when stored at an acidic $\mathrm{pH}$ of 4 . Glargine precipitates forming hexamers at physiological $\mathrm{pH}$ after injection into the subcutaneous space. Thereafter, glargine dissociates into insulin monomers that are slowly absorbed into the circulation. These properties result in a prolonged duration of action with a modest peak, and more consistent plasma insulin levels post injection when compared to neutral protamine Hagedorn (NPH) insulin. Several head to head studies have shown reduced nocturnal hypoglycemia when glargine is compared with NPH insulin. ${ }^{23}$ Glargine has been in use in the United States since 2000, and is now widely used in the management of type 1 and type 2 diabetes.

\section{Glargine effects on cardiovascular risk factors Blood pressure}

In the Outcome Reduction With Initial Glargine Intervention (ORIGIN) trial, among 12,537 subjects with impaired glucose tolerance, impaired fasting glucose or type 2 diabetes randomized to glargine or standard glycemic care, no blood pressure differences were seen. ${ }^{24}$ Direct comparison of exenatide vs glargine as add-on therapy to subjects with type 2 diabetes uncontrolled with oral anti-hyperglycemic agents in the Helping Evaluate Exenatide in overweight patients with diabetes compared with Long-Acting insulin (HEELA) study showed a non-significant increase in systolic blood pressure of $0.7 \mathrm{mmHg}$ with glargine, and a significant decrease of $2.9 \mathrm{mmHg}$ in the exenatide group after 26 weeks. ${ }^{25}$ This differential blood pressure effect is supported by meta-analyses of 32 glucagon-like peptide- 1 (GLP-1) agonist trials of which six trials directly compared a GLP-1 agonist and glargine with systolic blood pressure $3.46 \mathrm{mmHg}$ lower in the GLP-1 groups. ${ }^{26,27}$ There was a small increase in heart rate of 1-2 beats per minute with GLP-1 analogs, which may blunt some of the positive cardiovascular effects of blood pressure reduction.

\section{Lipid parameters}

Large cohort databases ${ }^{28}$ and meta-analyses examining the effects of insulin on lipids show reductions in total cholesterol (TC), low-density lipoprotein cholesterol (LDL-C), and triglycerides (TG) with mixed high-density lipoprotein cholesterol (HDL-C) results. ${ }^{29}$ The TG-lowering effect of insulin is believed to result from direct stimulation of lipoprotein lipase promoting clearance of TG-rich chylomicrons and inhibition of hormone-sensitive lipase blocking lipolysis. In more recent trials using glargine as add-on therapy, the lipid effects are mixed. In a 26 week trial of 40 patients who had glargine added to metformin and a sulfonylurea, glargine significantly reduced TC 9\%, LDL-C 9.4\%, and non-HDL-C 12.1\%, with neutral effects on TG and HDL-C. ${ }^{30}$ In another trial of 69 patients with type 2 diabetes, 51 weeks of glargine added to metformin led to a significant $28 \%$ decrease in free fatty acids with a non-significant $10 \%$ reduction in $\mathrm{TG}$ and no change 
in LDL-C, HDL-C or TC. ${ }^{31}$ In the Insulin glargine or NPH combined with metformin in type 2 diabetes (LANMET) study of 110 patients with type 2 diabetes who had glargine added to metformin, there were significant reductions in TG and increased HDL-C with no change in LDL-C after 9 months. ${ }^{32}$ Direct comparison of exenatide vs glargine as add-on therapy in a 26 week trial showed similar reductions in $\mathrm{HbA}_{1 \mathrm{c}}$ in both groups. Changes in LDL and TC favored exenatide showing a significantly greater reduction in LDL-C $(-0.25 \mathrm{vs}-0.07 \mathrm{mmol} / \mathrm{L})$ and a non-significantly greater reduction in TC $(-0.36 \mathrm{vs}-0.21 \mathrm{mmol} / \mathrm{L})$ with the GLP-1 agonist. ${ }^{25} \mathrm{TG}$ analysis revealed a non-significant trend toward greater reduction with glargine and a substantial reduction in both groups $(-0.33$ vs $-0.38 \mathrm{mmol} / \mathrm{L})$, with unchanged HDL-C in both groups. When the data from this study was combined with another 26 week add-on trial, a significantly greater reduction in TG was seen in the exenatide group. ${ }^{33}$ A reduction in TG was the only difference among lipid parameters observed in the ORIGIN trial in study subjects placed on glargine vs standard glycemic care. ${ }^{24}$

\section{Oxidative stress}

The effects of glargine on oxidative stress reduction have been mixed. In one trial, the addition of glargine to metformin and a sulfonylurea for 6 months reduced isoprostane (a marker of lipid peroxidation), but had no effect on C-reactive protein (a biomarker of inflammation), or plasminogen activator inhibitor-1 (an inhibitor of fibrinolysis). ${ }^{30}$ In another trial, glargine added to metformin did not improve P-Malondialdehyde (a marker of oxidative stress) in subjects with type 2 diabetes followed for 1 year. ${ }^{31}$

\section{Platelet reactivity}

An association of elevated insulin levels and increased platelet reactivity has been seen, though no trials of glargine and platelet reactivity have been performed. Studies of the insulin secretagogues repaglinide and glibenclamide, and prandial insulin aspart have shown increased platelet reactivity, ${ }^{34,35}$ whereas insulin sensitizers improved platelet reactivity. ${ }^{36,37}$

\section{Weight gain}

Glargine is associated with a weight gain of $1.2-1.4 \mathrm{~kg}$ at 6 months $^{38,39}$ and $3.8-3.9 \mathrm{~kg}$ at 1 year. ${ }^{40,41}$ A meta-analysis of four trials comparing detemir to glargine ranging from 24-52 weeks revealed a significantly greater mean weight gain of $0.91 \mathrm{~kg}$ in the glargine groups. ${ }^{42} \mathrm{~A}$ meta-analysis of six randomized clinical trials comparing NPH and glargine revealed a significant $0.33 \mathrm{~kg}$ greater weight gain in the glargine group. ${ }^{43}$ These data indicate that among comparative forms of long acting basal insulins, glargine may cause greater weight gain in individuals with type 2 diabetes.

\section{Hypoglycemia}

Hypoglycemia is the most common complication of insulin therapy, which when severe, can lead to coma, seizures, and death. Hypoglycemia is also a leading candidate for the association of insulin therapy with increased cardiovascular risk. A study of 21 patients with type 2 diabetes and known coronary artery disease who were being treated with insulin underwent simultaneous continuous glucose and cardiac Holter monitoring. Hypoglycemia was associated with subjective chest pain and ischemic electrocardiographic changes. ${ }^{44}$ In patients with both type 1 and type 2 diabetes, hypoglycemia has been associated with prolongation of the QT interval, ${ }^{45-48}$ a known risk factor for ventricular arrhythmias, severe hypertension, ${ }^{48}$ and elevated plasma catecholamine levels. ${ }^{45,46}$ Hypokalemia has been demonstrated to occur in patients presenting to the emergency room with severe hypoglycemia ${ }^{48}$ and in type 2 diabetes patients placed on a hyperinsulinemic glucose clamp. ${ }^{45}$ Catecholamine elevations and hypokalemia are known to potentiate the arrhythmogenic effect of QT prolongation. In a study of 25 patients with type 1 diabetes who underwent 24 hour electrocardiogram monitoring and continuous glucose monitoring, bradycardia and rhythm disturbances including ventricular ectopics, atrial ectopics and $\mathrm{P}$ wave abnormalities were revealed in $62 \%$ of nocturnal hypoglycemia episodes. ${ }^{47}$

A number of studies have examined the association of hypoglycemia and cardiovascular risk in subjects with type 2 diabetes. An evaluation of the 11,140 subjects in ADVANCE found that a prior episode of severe hypoglycemia was associated with a significant 2.88 -fold increased risk of a major macrovascular event and a significant 2.68-fold increased risk of cardiovascular death. ${ }^{49}$ In the ACCORD trial, the rates of hypoglycemia requiring assistance were three times greater in the intensive therapy group (15.9\% vs $5.0 \%)$ and $10.3 \%$ of patients in the intensive therapy group had hypoglycemia requiring medical assistance, as compared to $3.4 \%$ in the conventional therapy group. ${ }^{18} \mathrm{~A}$ retrospective analysis by the ACCORD research group showed an association between severe hypoglycemia and increased mortality risk in both treatment groups. However, only six deaths occurred within a month of the actual hypoglycemic event, leading the investigators to conclude that hypoglycemia was not directly responsible for the increased mortality within the intensive treatment group. ${ }^{50}$ In the VADT, severe hypoglycemia was a major predictor of 
cardiovascular death with a significant 4 -fold increased risk. ${ }^{51}$ However, deaths in VADT also occurred long after the most recent known severe hypoglycemic episode, mostly 12-18 months later. ${ }^{52}$ An analysis of five intensive diabetes control trials in patients with type 2 diabetes that included data from ACCORD and VADT concluded that hypoglycemia may not be causally related to cardiovascular events in type 2 diabetes, but may identify patients with multiple co-morbid illnesses who are more frail and more susceptible to both hypoglycemia and cardiovascular events. ${ }^{53}$ Using a conventional random effects meta-analysis of two randomized studies of type 2 diabetes and four administrative data bases including more than 900,000 subjects with type 2 diabetes, severe hypoglycemia was found to be strongly associated with a higher risk of cardiovascular disease (relative risk 2.05, $P<0.001$ ) that could not be explained alone by co-morbid disease. ${ }^{54}$ The Europe and Diabetes study (EURODIAB) in type 1 diabetes has not shown an association with hypoglycemia and cardiovascular events in subjects followed for 7 years. ${ }^{55}$ During the DCCT trial in type 1 diabetes, increased hypoglycemia in the intensive care group did not lead to increased cardiovascular risk over 6.5 years, nor after 30 years of follow-up. ${ }^{56,57}$

\section{Glargine and hypoglycemia}

Glargine use leads to less nocturnal hypoglycemia when compared to NPH insulin in subjects with both type $1^{58}$ and type 2 diabetes. ${ }^{59}$ A 2005 meta-analysis of studies in type 2 diabetes showed the risk of severe hypoglycemia and severe nocturnal hypoglycemia were reduced with insulin glargine by $46 \%$ and $59 \%$, respectively. ${ }^{23}$ Whether the reduction in hypoglycemia with glargine improves cardiovascular outcomes when compared with NPH has not been studied.

\section{Glargine and cardiovascular outcomes}

The ORIGIN trial ${ }^{24}$ is the only study to date dedicated to investigate the effects of glargine on cardiovascular outcomes. ORIGIN enrolled 12,537 patients with a mean age of 63.5 years, cardiovascular risk factors and impaired fasting glucose, impaired glucose tolerance or type 2 diabetes. Patients were randomized to receive glargine with a target fasting glucose of less than $95 \mathrm{mg} / \mathrm{dL}$ or standard glycemic care. At the end of the study, $83.6 \%$ of patients in the glargine group were on insulin compared with $11.4 \%$ in the standard-care group. The $\mathrm{HbA}_{1 \mathrm{c}}$ at year 7 was $6.2 \%$ in the glargine group and $6.5 \%$ in the standard-care group. The study found no difference in co-primary outcomes of nonfatal MI, nonfatal stroke or death from cardiovascular disease after a median follow-up of 6.2 years. Cardiovascular events were not increased despite an increased risk of hypoglycemia in the glargine group, who experienced 0.7 more severe episodes $(P<0.001)$ and eleven more suspected or confirmed episodes $(P<0.001)$ per 100 person-years than the standard-care group (Tables 1 and 2).

The strengths of ORIGIN include a large patient population with an increased risk of cardiovascular disease, a 6.2 year duration of follow-up, the large difference in sustained insulin use between groups, and the similar degree of $\mathrm{HbA}_{1 \mathrm{c}}$ lowering during the study. Patients in the standard-care group used metformin more commonly than patients in the glargine group (60\% vs 47\%), an agent known to be cardioprotective. ${ }^{16,60,61}$ It is unknown whether the neutral effect of glargine on cardiovascular outcomes would persist with a longer duration of follow-up or whether the effect would have been similar had enrolled subjects started with a $\mathrm{HbA}_{1 \mathrm{c}}$ of $8 \%$ or higher, a range more typically seen in patients started on basal insulin. There is evidence in ORIGIN that patients with new-onset type 2 diabetes may have done better than patients with previously diagnosed type 2 diabetes. Although non-significant, enrolled subjects with a new diagnosis of type 2 diabetes in the glargine group had 2.76 cardiovascular events per 100 person-years compared to the standard-care group who had 2.91 events per 100 person-years. In patients with prior type 2 diabetes, the glargine group had 3.03 events per 100 person-years compared to 2.91 events per 100 person-years in the standard therapy group.

Table I The Outcome Reduction With Initial Glargine Intervention (ORIGIN) trial: cardiovascular risk factors at study conclusion

\begin{tabular}{|c|c|c|c|}
\hline $\begin{array}{l}\text { Cardiovascular } \\
\text { risk factor }\end{array}$ & Glargine & $\begin{array}{l}\text { Standard } \\
\text { care }\end{array}$ & $P$-value \\
\hline Hemoglobin $\mathrm{A}_{\mathrm{Ic}}(\%)$ & 6.2 & 6.5 & \\
\hline $\begin{array}{l}\text { Severe hypoglycemia }{ }^{a} \\
\text { (no/l00 person years) }\end{array}$ & 1.00 & 0.31 & $P<0.001$ \\
\hline Systolic BP (mmHg) & $|4|$ & |4| & $P=0.40$ \\
\hline Diastolic BP (mmHg) & 79 & 79 & $P=0.90$ \\
\hline Mean heart rate (beats/min) & 69 & 69 & $P=0.08$ \\
\hline Mean male waist/hip ratio & 0.99 & 0.99 & $P=0.09$ \\
\hline Mean female waist/hip ratio & 0.92 & 0.91 & $P=0.08$ \\
\hline $\begin{array}{l}\text { Mean total cholesterol } \\
(\mathrm{mmol} / \mathrm{L})\end{array}$ & 4.53 & 4.58 & $P=0.09$ \\
\hline $\begin{array}{l}\text { Mean LDL cholesterol } \\
(\mathrm{mmol} / \mathrm{L})\end{array}$ & 2.64 & 2.63 & $P=0.50$ \\
\hline $\begin{array}{l}\text { Mean triglycerides } \\
(\mathrm{mmol} / \mathrm{L})\end{array}$ & 1.40 & 1.44 & $P<0.001$ \\
\hline
\end{tabular}

Notes: ${ }^{\text {TTh }}$ This category included any episode of hypoglycemia for which the patient required assistance and that was confirmed by a self-measured or laboratory plasma glucose level of $2 \mathrm{mmol}$ per liter ( $36 \mathrm{mg}$ per deciliter) or less or from which the patient recovered promptly after oral carbohydrate, intravenous glucose, or glucagon administration. Data from the ORIGIN trial investigators. ${ }^{24}$

Abbreviations: $\mathrm{BP}$, blood pressure; $\mathrm{HbA}_{\mathrm{Ic}}$, glycated hemoglobin; LDL, low-density lipoprotein; min, minute. 
Table 2 The ORIGIN trial: cardiovascular outcomes

\begin{tabular}{|c|c|c|c|c|c|c|}
\hline \multirow[t]{3}{*}{ Cardiovascular outcomes } & \multirow{2}{*}{\multicolumn{2}{|c|}{$\begin{array}{l}\text { Glargine } \\
N=6,264\end{array}$}} & \multirow{2}{*}{\multicolumn{2}{|c|}{$\begin{array}{l}\text { Standard care } \\
N=6,273\end{array}$}} & \multirow{3}{*}{$\begin{array}{l}\text { Hazard ratio } \\
(95 \% \mathrm{Cl})\end{array}$} & \multirow[t]{3}{*}{$P$-value } \\
\hline & & & & & & \\
\hline & No (\%) & $\begin{array}{l}\text { No/I } 00 \text { patient } \\
\text { years }\end{array}$ & No (\%) & $\begin{array}{l}\text { No/ } 100 \text { patient } \\
\text { years }\end{array}$ & & \\
\hline First coprimary outcome ${ }^{\mathrm{a}}$ & $I, 04 \mid(\mid 6.6)$ & 2.94 & $1,013(16.1)$ & 2.85 & $1.02(0.94-1.11)$ & $P=0.63$ \\
\hline Second coprimary outcome ${ }^{b}$ & $\mathrm{I}, 792(28.6)$ & 5.52 & $\mathrm{I}, 727(27.5)$ & 5.28 & $1.04(0.97-1.11)$ & $P=0.27$ \\
\hline Total mortality & $951(15.2)$ & 2.57 & $965(15.4)$ & 2.60 & $0.98(0.90-1.08)$ & $P=0.70$ \\
\hline Total strokes & $331(5.3)$ & 0.91 & $319(5.1)$ & 0.88 & $1.03(0.89-1.21)$ & $P=0.69$ \\
\hline Death from cardiovascular causes & $580(9.3)$ & 1.57 & $576(9.2)$ & 1.55 & $1.00(0.89-1.13)$ & $P=0.98$ \\
\hline $\begin{array}{l}\text { Hospitalization from congestive } \\
\text { heart failure }\end{array}$ & $310(4.9)$ & 0.85 & $343(5.5)$ & 0.95 & $0.90(0.77-1.05)$ & $P=0.16$ \\
\hline Revascularization & $908(14.5)$ & 2.69 & $860(13.7)$ & 2.52 & $1.06(0.96-1.16)$ & $P=0.24$ \\
\hline Angina & $709(11.3)$ & 2.07 & $743(11.8)$ & 2.17 & $0.95(0.85-1.05)$ & $P=0.29$ \\
\hline Unstable angina & $238(3.8)$ & 0.66 & $261(4.2)$ & 0.72 & $0.91(0.76-1.08)$ & $P=0.28$ \\
\hline New angina & $100(1.6)$ & 0.27 & $138(2.2)$ & 0.38 & $0.72(0.56-0.93)$ & $P=0.01$ \\
\hline \multirow[t]{3}{*}{ Worsening angina } & $455(7.3)$ & 1.29 & $446(7.1)$ & 1.26 & $1.02(0.89-1.16)$ & $P=0.80$ \\
\hline & $\begin{array}{l}\text { Glargine } \\
(n=533)\end{array}$ & & $\begin{array}{l}\text { Standard care } \\
(n=558)\end{array}$ & & $\begin{array}{l}\text { Difference (glargine, } \\
\text { standard care) }\end{array}$ & \\
\hline & SLSM & & SLSM & & LSM & \\
\hline $\begin{array}{l}\text { Maximum CIMT for } 12 \text { carotid } \\
\text { artery segments }\end{array}$ & $0.0234 \pm 0.0015$ & & $0.0264 \pm 0.0015$ & & $-0.0030 \pm 0.0021$ & $P=0.145$ \\
\hline $\begin{array}{l}\text { Maximum CIMT for the } 4 \text { common } \\
\text { carotid artery segments }\end{array}$ & $0.0126 \pm 0.0012$ & & $0.0158 \pm 0.0012$ & & $-0.0033 \pm 0.0017$ & $P=0.049$ \\
\hline $\begin{array}{l}\text { Maximum CIMT for the } 8 \text { common } \\
\text { carotid and bifurcation segments }\end{array}$ & $0.0209 \pm 0.0015$ & & $0.0254 \pm 0.0015$ & & $-0.0045 \pm 0.0021$ & $P=0.032$ \\
\hline
\end{tabular}

Notes: ${ }^{a}$ The first coprimary outcome was nonfatal myocardial infarction, nonfatal stroke, or death from cardiovascular causes and these events plus revascularization or hospitalization for heart failure; 'the second coprimary outcome was nonfatal myocardial infarction, nonfatal stroke, death from cardiovascular causes, revascularization or hospitalization for heart failure. Data from The ORIGIN trial investigators, ${ }^{24}$ and American Diabetes Association, Diabetes Care, American Diabetes Association, 2013. Copyright and all rights reserved. Material from this publication has been used with the permission of American Diabetes Association. ${ }^{63}$

Abbreviations: $\mathrm{Cl}$, confidence interval; CIMT, carotid intima-media thickness; SLSM, slope least square mean \pm SE (mm/year); LSM, least square mean \pm SE (mm/year); SE, standard error.

Data from 65,619 patients in the United States with type 2 diabetes from the PharMetrics claims database show a similar incidence of heart failure and stroke for all medium to long-acting insulins including glargine. After adjusting for age, sex, history of hypertension and hyperlipidemia, days' supply of insulin and diabetes duration, a non-significant $19 \%$ reduction in MI was seen in individuals prescribed glargine insulin compared to other intermediate or long-acting insulins $(P=0.075){ }^{62}$

\section{Glargine and CIMT}

In a sub-study of 1,184 subjects in the ORIGIN trial having impaired fasting glucose, impaired glucose tolerance or type 2 diabetes and randomized to glargine or standard glycemic care, CIMT was measured at baseline and after a median follow-up of 4.9 years. ${ }^{63}$ The primary endpoint, annualized rate of change in maximum CIMT at the common carotid, carotid bifurcation and internal carotid artery segments was non-significantly reduced $(P=0.145)$ in the glargine group. However, secondary endpoints including the annualized rate of change in maximum CIMT for the common carotid $(P=0.049)$ and common carotid plus bifurcation ( $P=0.032)$ were observed in the glargine group (Table 2).

\section{Glargine and microvascular complications}

Improved glycemic control using insulin reduces the risk of developing microvascular complications. Among patients with type 1 diabetes in the DCCT, ${ }^{8}$ every $10 \%$ reduction in $\mathrm{HbA}_{1 \mathrm{c}}$ reduced the risk of retinopathy progression by $44 \%$, microalbuminuria by $25 \%$, macroalbuminuria by $44 \%$, and neuropathy by $30 \%{ }^{64}$ After up to 30 years of follow-up of patients intensively controlled in DCCT, sustained reductions in nephropathy, neuropathy, and retinopathy were observed, in addition to reductions in severe retinal and renal outcomes. ${ }^{57}$

The Kumamoto study randomized 110 insulin-treated patients with type 2 diabetes to intensive vs standard insulin therapy leading to a mean $\mathrm{HbA}_{1 \mathrm{c}}$ difference of $2.2 \%$ 
(7.2\% vs 9.4\%). ${ }^{65}$ After a mean follow-up of 8 years in the combined primary and secondary prevention cohorts, significant risk reductions of $63 \%$ were observed for retinopathy and $74 \%$ for nephropathy. Significant improvements in median nerve conduction velocity were also seen in the intensive insulin therapy subjects vs significant reductions in median nerve conduction velocity among conventional insulin therapy subjects.

A meta-analysis of outcomes from ACCORD, ADVANCE, and VADT found that intensive therapy of older adults with type 2 diabetes, the majority of whom were insulin-treated and followed for a mean 3.5-5.6 years, resulted in a $10 \%$ reduction in microalbuminuria, but no significant change in other microvascular complications. ${ }^{66}$

As glycemia and the incidence of microvascular diabetes complications follow a log-linear relationship, it becomes increasingly difficult to demonstrate a microvascular benefit of glucose-lowering when the $\mathrm{HbA}_{1 \mathrm{c}}$ level is close to normal. In an analysis of the ORIGIN trial, after a median 6.2 years of follow-up, a reduced risk of microvascular outcomes was seen in subjects randomized to glargine with a baseline $\mathrm{HbA}_{1 \mathrm{c}}$ level $\geq 6.4 \% .{ }^{67}$ A larger median $\mathrm{HbA}_{1 \mathrm{c}}$ difference between subjects randomized to glargine vs standard-care whose baseline $\mathrm{HbA}_{1 \mathrm{c}}$ was $\geq 6.4 \%$ vs $<6.4 \%$ ( $0.33 \%$ vs $0.22 \%, P<0.0001)$ presumably explains the difference seen in microvascular complications between groups.

\section{Glargine and cancer}

Epidemiological evidence supports the link between diabetes and an increased incidence of cancers, after the adjustment for confounding factors including age and obesity ${ }^{68,69}$ The first concern that glargine may be an inciting factor in cancer arose from evidence that glargine has increased insulin like growth factor-1 (IGF-1) receptor affinity and showed increased mitogenicity in a human osteosarcoma cell line when compared to human insulin. ${ }^{70}$ Further investigation in mice and rats did not show a carcinogenic potential for glargine. ${ }^{71}$ In 2009, concurrently released retrospective cohort studies showed an association between insulin use and colorectal/pancreatic cancer with no change in prostate or breast cancer rates, ${ }^{72}$ a dose dependent increase in cancer risk for glargine vs human insulin, ${ }^{73}$ a 2 -fold increased risk of breast cancer in women taking glargine, ${ }^{74}$ which was later negated in follow-up studies in the same population, ${ }^{75}$ and higher rates of all cancers. ${ }^{76}$ These retrospective analyses led to scrutiny of the possible carcinogenic effects of glargine. Small randomized trials and meta-analyses of randomized trials have shown no association between glargine and cancer when followed prospectively. ${ }^{77,78}$ The ORIGIN trial is the most rigorous analysis of glargine and cancer outcomes performed to date. After 6 years of follow-up, no association was found between exposure to glargine and cancer (hazard ratio [HR] 1.00) or cancer death (HR 0.94). ${ }^{24}$ A separate analysis showed that post-randomization $\mathrm{HbA}_{1 \mathrm{c}}$ levels, glucose-lowering therapies (including metformin), and body mass index did not affect cancer outcomes. ${ }^{79}$ Recently, an analysis found that cancer risk increases with duration of diabetes and the requirement of insulin to control blood glucose. ${ }^{80}$ It has since been suggested that the known relationship between diabetes and cancer may be mediated by a number of other diabetes specific factors including chronic hyperglycemia, insulin resistance, hyperinsulinemia, lifestyle, oxidative stress, increased growth factor levels, excessive inflammation, and altered angiogenesis. ${ }^{81}$ The low doses of glargine used in the ORIGIN trial $(0.3-0.4 \mathrm{u} / \mathrm{kg})$ and the shorter duration of diabetes among participants may have contributed to the low rates of cancer observed. Recent studies have revealed that glargine largely dissociates into metabolites which have a similar affinity for the insulin receptor, but a much lower affinity for the IGF-1 receptor and consequently a much lower mitogenicity. ${ }^{82}$ This decreased in-vivo mitogenicity likely explains the differences in the cell-based studies and clinical use in human patients. At this time, there is insufficient data to support an increased risk of malignancy due to glargine.

\section{Conclusion}

The association of hyperinsulinemia with increased cardiovascular risk has led to a justifiable concern that exogenous insulin administration could increase the incidence of cardiovascular events in patients with type 1 and type 2 diabetes. Insulin has been shown to have both cardioprotective and atherosclerosis-promoting effects in laboratory animal studies. However, human trials have not shown insulin to increase cardiovascular event rates. Indeed, intensive diabetes control using insulin in type 1 diabetes patients in EDIC, or insulin or a sulfonylurea in type 2 diabetes patients in UKPDS led to improved long-term cardiovascular outcomes. Such data support the concept that hyperinsulinemia is a marker of insulin resistance, a condition associated with numerous cardiovascular risk factors and increased cardiovascular risk, rather than exogenous insulin being a risk factor for cardiovascular disease. Glargine lowers TG, leads to a modest weight gain, decreases hypoglycemia when compared with NPH, and has a neutral effect on blood pressure. The ORIGIN trial, a dedicated cardiovascular 
outcomes trial of glargine, demonstrated no increased cardiovascular risk.

Contemporary clinical diabetes trials routinely employ greater cardiovascular risk factor control, especially of elevated lipids and blood pressure, and are therefore expected to have lower background cardiovascular event rates. For this reason, future definitive cardiovascular outcomes trials of anti-hyperglycemic agents may need to be extended beyond 5-6 years.

Randomized trials of intensive therapy in type 2 diabetes with high rates of insulin use have demonstrated an association of severe hypoglycemia and adverse cardiovascular events. Whether hypoglycemia is contributing the increased cardiovascular risk or simply a marker of a more ill, higher risk patient population remains controversial. Clinicians should be aware of the hypoglycemic risk of all insulins, and should work to minimize hypoglycemia especially in higher risk patients.

\section{Disclosure}

The authors have no conflicts of interest to disclose.

\section{References}

1. Stout RW. Insulin and atheroma: 20-yr perspective. Diabetes Care. 1990;13(6):631-654.

2. Pyorala M, Miettinen H, Laakso M, Pyorala K. Hyperinsulinemia Predicts Coronary Heart Disease Risk in Healthy Middle-aged Men: The 22-Year Follow-up Results of the Helsinki Policemen Study. Circulation. 1998;98(5):398-404.

3. Sato Y, Shiraishi S, Oshida Y, Ishiguro T, Sakamoto N. Experimental atherosclerosis-like lesions induced by hyperinsulinism in Wistar rats. Diabetes. 1989;38(1):91-96.

4. Joseph JJ, Golden SH. Type 2 diabetes and cardiovascular disease: what next? Curr Opin Endocrinol Diabetes Obes. 2014;21(2):109-120.

5. Stark Casagrande S, Fradkin JE, Saydah SH, Rust KF, Cowie CC. The prevalence of meeting $\mathrm{A} 1 \mathrm{C}$, blood pressure, and LDL goals among people with diabetes, 1988-2010. Diabetes Care. 2013;36(8): 2271-2279.

6. Taylor KS, Heneghan CJ, Farmer AJ, et al. All-Cause and Cardiovascular Mortality in Middle-Aged People With Type 2 Diabetes Compared With People Without Diabetes in a Large UK Primary Care Database. Diabetes Care. 2013;36(8):2366-2371.

7. Haffner SM, Lehto S, Rönnemaa T, Pyörälä K, Laakso M. Mortality from Coronary Heart Disease in Subjects with Type 2 Diabetes and in Nondiabetic Subjects with and without Prior Myocardial Infarction. N Engl J Med. 1998;339(4):229-234.

8. Nathan DM, Cleary PA, Backlund JY, et al. Intensive diabetes treatment and cardiovascular disease in patients with type 1 diabetes. $N$ Engl $J$ Med. 2005;353(25):2643-2653.

9. The Diabetes Control and Complications Trial Research Group. The Effect of Intensive Treatment of Diabetes on the Development and Progression of Long-Term Complications in Insulin-Dependent Diabetes Mellitus. N Engl J Med. 1993;329(14):977-986.

10. Cleary PA, Orchard TJ, Genuth S, et al. The Effect of Intensive Glycemic Treatment on Coronary Artery Calcification in Type 1 Diabetic Participants of the Diabetes Control and Complications Trial/Epidemiology of Diabetes Interventions and Complications (DCCT/EDIC) Study. Diabetes. 2006;55(12):3556-3565.
11. Epidemiology of Diabetes Interventions and Complications Research Group. Effect of intensive diabetes treatment on carotid artery wall thickness in the epidemiology of diabetes interventions and complications. Epidemiology of Diabetes Interventions and Complications (EDIC) Research Group. Diabetes. 1999;48(2):383-390.

12. Nathan DM, Lachin J, Cleary P, et al. Intensive diabetes therapy and carotid intima-media thickness in type 1 diabetes mellitus. $N$ Engl $J$ Med. 2003;348(23):2294-2303.

13. Polak JF, Backlund JY, Cleary PA, et al. Progression of Carotid Artery Intima-Media Thickness During 12 Years in the Diabetes Control and Complications Trial/Epidemiology of Diabetes Interventions and Complications (DCCT/EDIC) Study. Diabetes. 2011;60(2):607-613.

14. UK Prospective Diabetes Study Group. Intensive blood-glucose control with sulphonylureas or insulin compared with conventional treatment and risk of complications in patients with type 2 diabetes (UKPDS 33). UK Prospective Diabetes Study (UKPDS) Group. Lancet. 1998;352(9131):837-853.

15. Holman RR, Paul SK, Bethel MA, Matthews DR, Neil HA. 10-year follow-up of intensive glucose control in type 2 diabetes. $N$ Engl J Med. 2008;359(15):1577-1589.

16. UK Prospective Diabetes Study Group. Effect of intensive blood-glucose control with metformin on complications in overweight patients with type 2 diabetes (UKPDS 34). UK Prospective Diabetes Study (UKPDS) Group. Lancet. 1998;352(9131):854-865.

17. Stratton IM,Adler AI, Neil HA, et al. Association of glycaemia with macrovascular and microvascular complications of type 2 diabetes (UKPDS 35): prospective observational study. BMJ. 2000;321(7258):405-412.

18. Action to Control Cardiovascular Risk in Diabetes Study Group, Gerstein HC, Miller ME, et al. Effects of intensive glucose lowering in type 2 diabetes. $N$ Engl J Med. 2008;358(24):2545-2559.

19. ADVANCE Collaborative Group, Patel A, MacMahon S, et al. Intensive blood glucose control and vascular outcomes in patients with type 2 diabetes. N Engl J Med. 2008;358(24):2560-2572.

20. Duckworth W, Abraira C, Moritz T, et al. Glucose control and vascular complications in veterans with type 2 diabetes. $N$ Engl J Med. 2009;360(2):129-139.

21. Inzucchi SE, Bergenstal RM, Buse JB, et al. Management of Hyperglycemia in Type 2 Diabetes: A Patient-Centered Approach: Position Statement of the American Diabetes Association (ADA) and the European Association for the Study of Diabetes (EASD). Diabetes Care. 2012;35(6):1364-1379.

22. American Diabetes Association. Standards of medical care in diabetes 2014. Diabetes Care. 2014;37 Suppl 1:S14-S80.

23. Rosenstock J, Dailey G, Massi-Benedetti M, Fritsche A, Lin Z, Salzman A. Reduced Hypoglycemia Risk With Insulin Glargine A meta-analysis comparing insulin glargine with human NPH insulin in type 2 diabetes. Diabetes Care. 2005;28(4):950-955.

24. The ORIGIN Trial Investigators, Gerstein HC, Bosch J. Basal Insulin and Cardiovascular and Other Outcomes in Dysglycemia. $N$ Engl $J$ Med. 2012;367(4):319-328.

25. Davies MJ, Donnelly R, Barnett AH, Jones S, Nicolay C, Kilcoyne A. Exenatide compared with long-acting insulin to achieve glycaemic control with minimal weight gain in patients with type 2 diabetes: results of the Helping Evaluate Exenatide in patients with diabetes compared with Long-Acting insulin (HEELA) study. Diabetes Obes Metab. 2009;11(12):1153-1162.

26. Robinson LE, Holt TA, Rees K, Randeva HS, O'Hare JP. Effects of exenatide and liraglutide on heart rate, blood pressure and body weight: systematic review and meta-analysis. BMJ Open. 2013;3(1)pii: e001986.

27. Wang B, Zhong J, Lin H, et al. Blood pressure-lowering effects of GLP-1 receptor agonists exenatide and liraglutide: a meta-analysis of clinical trials. Diabetes Obes Metab. 2013;15(8):737-749.

28. Horton ES, Silberman C, Davis KL, Berria R. Weight Loss, Glycemic Control, and Changes in Cardiovascular Biomarkers in Patients with Type 2 Diabetes Receiving Incretin Therapies or Insulin in a Large Cohort Database. Diabetes Care. 2010;33(8):1759-1765. 
29. Chaudhuri A, Dandona P. Effects of insulin and other antihyperglycaemic agents on lipid profiles of patients with diabetes. Diabetes Obes Metab. 2011;13(10):869-879.

30. Reynolds LR, Kingsley FJ, Karounos DG, Tannock LR. Differential effects of rosiglitazone and insulin glargine on inflammatory markers, glycemic control, and lipids in type 2 diabetes. Diabetes Res Clin Pract. 2007;77(2):180-187.

31. Bunck MC, Corner A, Eliasson B, et al. One-year treatment with exenatide vs Insulin Glargine: Effects on postprandial glycemia, lipid profiles, and oxidative stress. Atherosclerosis. 2010;212(1): 223-229.

32. Yki-Järvinen H, Kauppinen-Makelin R, Tiikkainen M, et al. Insulin glargine or NPH combined with metformin in type 2 diabetes: the LANMET study. Diabetologia. 2006;49(3):442-451.

33. Li WX, Gou JF, Tian JH, Yan X, Yang L. Glucagon-like peptide-1 receptor agonists versus insulin glargine for type 2 diabetes mellitus: A systematic review and meta-analysis of randomized controlled trials. Curr Ther Res Clin Exp. 2010;71(4):211-238.

34. Spectre G, Ostenson CG, Li N, Hjemdahl P. Postprandial Platelet Activation is Related to Postprandial Plasma Insulin Rather Than Glucose in Patients with Type 2 Diabetes. Diabetes. 2012;61(9): 2380-2384.

35. Yngen M, Ostenson CG, Hjemdahl P, Wallen NH. Meal-induced platelet activation in Type 2 diabetes mellitus: effects of treatment with repaglinide and glibenclamide. Diabet Med. 2006;23(2): 134-140.

36. Formoso G, De Filippis EA, Michetti N, et al. Decreased in vivo oxidative stress and decreased platelet activation following metformin treatment in newly diagnosed type 2 diabetic subjects. Diabetes Metab Res Rev. 2008;24(3):231-237.

37. Khanolkar MP, Morris RH, Thomas AW, et al. Rosiglitazone produces a greater reduction in circulating platelet activity compared with gliclazide in patients with type 2 diabetes mellitus - an effect probably mediated by direct platelet PPAR $\gamma$ activation. Atherosclerosis. 2008;197(2):718-724.

38. Swinnen SG, Dain MP, Aronson R, et al. A 24-Week, Randomized, Treat-to-Target Trial Comparing Initiation of Insulin Glargine OnceDaily With Insulin Detemir Twice-Daily in Patients with Type 2 Diabetes Inadequately Controlled on Oral Glucose-Lowering Drugs. Diabetes Care. 2010;33(6):1176-1178.

39. Raskin P, Gylvin T, Weng W, Chaykin L. Comparison of insulin detemir and insulin glargine using a basal-bolus regimen in a randomized, controlled clinical study in patients with type 2 diabetes. Diabetes Metab Res Rev. 2009;25(6):542-548.

40. Hollander P, Cooper J, Bregnhøj J, Pedersen CB. A 52-week, multinational, open-label, parallel-group, noninferiority, treat-to-target trial comparing insulin detemir with insulin glargine in a basal-bolus regimen with mealtime insulin aspart in patients with type 2 diabetes. Clin Ther. 2008;30(11):1976-1987.

41. Rosenstock J, Davies M, Home PD, Larsen J, Koenen C, Schernthaner G. A randomised, 52-week, treat-to-target trial comparing insulin detemir with insulin glargine when administered as add-on to glucose-lowering drugs in insulin-naive people with type 2 diabetes. Diabetologia. 2008;51(3):408-416.

42. Swinnen SG, Simon A, Holleman F, Hoekstra JB, DeVries JH. Insulin detemir versus insulin glargine for type 2 diabetes mellitus. Cochrane Database Syst Rev. 2011;(7):CD006383.

43. Bazzano LA, Lee LJ, Shi L, Reynolds K, Jackson JA, Fonseca V. Safety and efficacy of glargine compared with NPH insulin for the treatment of Type 2 diabetes: a meta-analysis of randomized controlled trials. Diabet Med. 2008;25(8):924-932.

44. Desouza C, Salazar H, Cheong B, Murgo J, Fonseca V. Association of Hypoglycemia and Cardiac Ischemia A study based on continuous monitoring. Diabetes Care. 2003;26(5):1485-1489.

45. Marques JL, George E, Peacey SR, et al. Altered ventricular repolarization during hypoglycaemia in patients with diabetes. Diabet Med. 1997;14(8):648-654.
46. Robinson RT, Harris ND, Ireland RH, Macdonald IA, Heller SR. Changes in cardiac repolarization during clinical episodes of nocturnal hypoglycaemia in adults with Type 1 diabetes. Diabetologia. 2004;47(2):312-315.

47. Gill GV, Woodward A, Casson IF, Weston PJ. Cardiac arrhythmia and nocturnal hypoglycaemia in type 1 diabetes - the 'dead in bed' syndrome revisited. Diabetologia. 2009;52(1):42-45.

48. Tsujimoto T, Yamamoto-Honda R, Kajio H, et al. Vital signs, QT prolongation, and newly diagnosed cardiovascular disease during severe hypoglycemia in type 1 and type 2 diabetic patients. Diabetes Care. 2014;37(1):217-225.

49. Zoungas S, Patel A, Chalmers J, et al. Severe hypoglycemia and risks of vascular events and death. N Engl J Med. 2010;363(15):1410-1418.

50. Bonds DE, Miller ME, Bergenstal RM, et al. The association between symptomatic, severe hypoglycaemia and mortality in type 2 diabetes: retrospective epidemiological analysis of the ACCORD study. BMJ. 2010;340:b4909.

51. Schernthaner G. Diabetes and Cardiovascular Disease: is intensive glucose control beneficial or deadly? Lessons from ACCORD, ADVANCE, VADT, UKPDS, PROactive, and NICE-SUGAR. Wien Med Wochenschr. 2010;160(1-2):8-19.

52. Boucai L, Southern WN, Zonszein J. Hypoglycemia-associated Mortality is Not Drug-associated but Linked to Comorbidities. Am J Med. 2011;124(11):1028-1035.

53. Yakubovich N, Gerstein HC. Serious Cardiovascular Outcomes in Diabetes: The Role of Hypoglycemia. Circulation. 2011;123(3): 342-348.

54. Goto A, Arah OA, Goto M, Terauchi Y, Noda M. Severe hypoglycaemia and cardiovascular disease: systematic review and meta-analysis with bias analysis. BMJ. 2013;347:f4533.

55. Gruden G, Barutta F, Chaturvedi N, et al. Severe Hypoglycemia and Cardiovascular Disease Incidence in Type 1 Diabetes: The EURODIAB Prospective Complications Study. Diabetes Care. 2012;35(7): 1598-1604.

56. Diabetes Control and Complications Trial Research Group. Hypoglycemia in the Diabetes Control and Complications Trial. The Diabetes Control and Complications Trial Research Group. Diabetes. 1997;46(2):271-286.

57. Nathan DM, Bayless M, Cleary P, et al. Diabetes Control and Complications Trial/Epidemiology of Diabetes Interventions and Complications Study at 30 Years: Advances and Contributions. Diabetes. 2013;62(12):3976-3986.

58. Ratner RE, Hirsch IB, Neifing JL, Garg SK, Mecca TE, Wilson CA. Less hypoglycemia with insulin glargine in intensive insulin therapy for type 1 diabetes. US Study Group of Insulin Glargine in Type 1 Diabetes. Diabetes Care. 2000;23(5):639-643.

59. Yki-Järvinen H, Dressler A, Ziemen M; HOE 901/300s Study Group. Less nocturnal hypoglycemia and better post-dinner glucose control with bedtime insulin glargine compared with bedtime NPH insulin during insulin combination therapy in type 2 diabetes. Diabetes Care. 2000;23(8):1130-1136.

60. Hong J, Zhang Y, Lai S, et al. Effects of Metformin Versus Glipizide on Cardiovascular Outcomes in Patients With Type 2 Diabetes and Coronary Artery Disease. Diabetes Care. 2013;36(5):1304-1311.

61. Selvin E, Bolen S, Yeh HC, et al. Cardiovascular outcomes in trials of oral diabetes medications: a systematic review. Arch Intern Med. 2008;168(19):2070-2080.

62. Juhaeri J, Gao S, Dai WS. Incidence rates of heart failure, stroke, and acute myocardial infarction among Type 2 diabetic patients using insulin glargine and other insulin. Pharmacoepidemiol Drug Saf. 2009;18(6):497-503.

63. Lonn EM, Bosch J, Diaz R, et al. Effect of Insulin Glargine and n-3FA on Carotid Intima-Media Thickness in People With Dysglycemia at High Risk for Cardiovascular Events: The Glucose Reduction and Atherosclerosis Continuing Evaluation Study (ORIGIN-GRACE). Diabetes Care. 2013;36(9):2466-2474.

64. The Diabetes Control and Complications Trial Research Group. The relationship of glycemic exposure (HbAlc) to the risk of development and progression of retinopathy in the Diabetes Control and Complications Trial. Diabetes. 1995;44(8):968-983. 
65. Shichiri M, Kishikawa H, Ohkubo Y, Wake N. Long-term results of the Kumamoto Study on optimal diabetes control in type 2 diabetic patients. Diabetes Care. 2000;23 Suppl 2:B21-B29.

66. Boussageon R, Bejan-Angoulvant T, Saadatien-Elahi M, et al. Effect of intensive glucose lowering treatment on all cause mortality, cardiovascular death, and microvascular events in type 2 diabetes: meta-analysis of randomised controlled trials. BMJ. 2011;343:d4169.

67. ORIGIN trial investigators, Gilbert RE, Mann JF, et al. Basal insulin glargine and microvascular outcomes in dysglycaemic individuals: results of the Outcome Reduction with an Initial Glargine Intervention (ORIGIN) trial. Diabetologia. 2014;57(7):1325-1331.

68. Greenwood M, Wood F. The Relation between the Cancer and Diabetes Death-rates. J Hyg (Lond). 1914;14(1):83-118.

69. Nicolucci A. Epidemiological aspects of neoplasms in diabetes. Acta Diabetol. 2010;47(2):87-95.

70. Kurtzhals P, Schaffer L, Sorensen A, et al. Correlations of receptor binding and metabolic and mitogenic potencies of insulin analogs designed for clinical use. Diabetes. 2000;49(6):999-1005.

71. Stammberger I, Bube A, Durchfeld-Meyer B, Donaubauer H, Troschau G. Evaluation of the Carcinogenic Potential of Insulin Glargine (LANTUS) in Rats and Mice. Int J Toxicol. 2002;21(3): 171-179.

72. Currie CJ, Poole CD, Gale EA. The influence of glucose-lowering therapies on cancer risk in type 2 diabetes. Diabetologia. 2009;52(9): 1766-1777.

73. Hemkens LG, Grouven U, Gunster C, et al. Risk of malignancies in patients with diabetes treated with human insulin or insulin analogues: a cohort study. Diabetologia. 2009;52(9):1732-1744.

74. Jonasson JM, Ljung R, Talback M, Haglund B, Gudbjornsdottir S, Steineck G. Insulin glargine use and short-term incidence of malignancies - a population-based follow-up study in Sweden. Diabetologia. 2009;52(9):1745-1754.
75. Ljung R, Talback M, Haglund B, Jonasson JM, Gudbjornsdottir S, Steineck G. Insulin glargine use and short-term incidence of breast cancer - a four-year population-based observation. Acta Oncol. 2012;51(3):400-402.

76. Colhoun HM; SDRN Epidemiology Group. Use of insulin glargine and cancer incidence in Scotland: a study from the Scottish Diabetes Research Network Epidemiology Group. Diabetologia. 2009;52(9): 1755-1765.

77. Rosenstock J, Fonseca V, McGill JB, et al. Similar risk of malignancy with insulin glargine and neutral protamine Hagedorn (NPH) insulin in patients with type 2 diabetes: findings from a 5 year randomised, open-label study. Diabetologia. 2009;52(9):1971-1973.

78. Home PD, Lagarenne P. Combined randomised controlled trial experience of malignancies in studies using insulin glargine. Diabetologia. 2009;52(12):2499-2506.

79. Bordeleau L, Yakubovich N, Dagenais GR, et al. The Association of Basal Insulin Glargine and/or n-3 Fatty Acids with Incident Cancers in Patients With Dysglycemia. Diabetes Care. 2014;37(5):1360-1366.

80. Li C, Zhao G, Okoro CA, Wen XJ, Ford ES, Balluz LS. Prevalence of Diagnosed Cancer According to Duration of Diagnosed Diabetes and Current Insulin Use Among US Adults With Diagnosed Diabetes: Findings from the 2009 Behavioral Risk Factor Surveillance System. Diabetes Care. 2013;36(6):1569-1576.

81. Sen S, He Y, Koya D, Kanasaki K. Cancer biology in diabetes. J Diabetes Investig. 2014;5(3):251-264.

82. Sommerfeld MR, Muller G, Tschank G, et al. In Vitro Metabolic and Mitogenic Signaling of Insulin Glargine and its Metabolites. PLoS One. 2010;5(3):e9540
Vascular Health and Risk Management

\section{Publish your work in this journal}

Vascular Health and Risk Management is an international, peerreviewed journal of therapeutics and risk management, focusing on concise rapid reporting of clinical studies on the processes involved in the maintenance of vascular health; the monitoring, prevention and treatment of vascular disease and its sequelae; and the involvement of

\section{Dovepress}

metabolic disorders, particularly diabetes. This journal is indexed on PubMed Central and MedLine. The manuscript management system is completely online and includes a very quick and fair peer-review system, which is all easy to use. Visit http://www.dovepress.com/ testimonials.php to read real quotes from published authors. 